\title{
POLA HERNIA INGUINALIS LATERALIS DI RSUP PROF. DR. R. D. KANDOU MANADO PERIODE AGUSTUS 2012 - JULI 2014
}

\author{
${ }^{1}$ Claudia G. Rawis \\ ${ }^{2}$ Hilman P. Limpeleh \\ ${ }^{2}$ Paul A. V. Wowiling
}

\author{
${ }^{1}$ Kandidat Skripsi Fakultas Kedokteran Universitas Sam Ratulangi Manado, \\ ${ }^{2}$ Bagian/SMF Bedah RSUP Prof. Dr. R. D. Kandou Manado \\ Email: claudiarawis@gmail.com
}

\begin{abstract}
Lateral inguinal hernia is a protrusion of the abdominal wall that occurs in the inguinal region adjacent to the lateral inferior epigastric vessels. This hernia can occur due to congenital or acquired causes. Approximately $80-90 \%$ of laateral inguinal hernia was found in men and $10 \%$ in women. This study aimed to determine the pattern of lateral inguinal hernia in Prof. Dr. R. D. Kandou Manado period August 2012 - July 2014. This was a retrospective descriptive study using secondary data of lateral inguinal hernia patients in the Prof. Dr. R. D. Kandou General Hospital Manado. The results showed that there were 146 lateral inguinal hernia patients in Prof. Dr. R. D. Kandou General Hospital Manado during the period August 2012 - July 2014. The most common age group was elderly (27.4\%). Male sex was the majority of the lateral inguinal hernia patients (99.3\%). Patients with the layout of the lateral inguinal hernia on the right were the most cases (60.3\%). The type according to the progress of the hernia was reponible (74.0\%). The most frequent management of the lateral inguinal hernia patients was herniotomy with the use of mesh (73.3\%).
\end{abstract}

Keywords: hernia, pattern of lateral inguinal hernia

\begin{abstract}
Abstrak: Hernia inguinalis lateralis adalah suatu penonjolan dinding perut yang terjadi di daerah inguinal sebelah lateral pembuluh epigastrika inferior. Penyebab hernia inguinalis lateralis yaitu kongenital atau karena sebab yang didapat. Sekitar $80-90 \%$ ditemukan pada laki-laki dan $10 \%$ pada perempuan. Penelitian ini bertujuan untuk mengetahui pola hernia inguinalis lateralis di RSUP Prof. Dr. R. D. Kandou Manado periode Agustus 2012 - Juli 2014. Penelitian ini bersifat deskriptif retrospektif menggunakan data sekunder pasien hernia inguinalis lateralis di RSUP Prof. Dr. R. D. Kandou Manado. Hasil penelitian memperlihatkan 146 pasien hernia inguinalis lateralis di RSUP Prof. Dr. R. D. Kandou Manado selama periode waktu tersebut. Kelompok umur tersering ialah manula atau $>65$ tahun (27,4\%). Jenis kelamin laki-laki merupakan mayoritas (99,3\%). Pasien hernia inguinalis lateralis dengan letak di sebelah kanan merupakan kasus terbanyak (60,3\%). Jenis menurut perlangsungan hernia yang tersering ialah hernia inguinalis lateralis reponibel $(74,0 \%)$. Penanganan hernia inguinalis lateralis yang paling sering dilakukan ialah herniotomi disertai penggunaan mesh $(73,3 \%)$.
\end{abstract}

Kata kunci: hernia, pola hernia inguinalis lateralis

Peningkatan derajat ekonomi sangat memengaruhi gaya hidup sehari-hari, misalnya pola aktifitas dan pekerjaan disamping turut berdampak terhadap kesehatan antara lain terjadinya hernia.
Hampir 75\% dari hernia abdominalis merupakan hernia ingunalis. ${ }^{1,2}$

Hernia inguinalis dibagi menjadi hernia ingunalis lateralis dan hernia ingunalis medialis. Hernia ingunalis 
lateralis ditemukan lebih banyak dua per tiga dari hernia ingunalis medialis. Hernia inguinalis lateralis mempunyai nama lain yaitu hernia indirect oleh karena keluar-nya tidak langsung menembus dinding abdomen. Hernia inguinalis lateralis adalah suatu penonjolan dinding perut yang terjadi di daerah inguinal disebelah lateral pembuluh epigastrika inferior. Penyebab terjadinya hernia inguinalis lateralis yaitu karena anomali kongenital atau karena sebab yang didapat., ${ }^{1,2}$

Pada hernia inguinalis lateralis keluhan pada orang dewasa berupa benjolan di lipat paha yang timbul pada waktu mengejan, batuk, atau mengangkat beban berat dan menghilang waktu istirahat baring. Sekitar 80-90\% dari hernia inguinalis lateralis ditemukan pada laki-laki dan 10\% pada perempuan. Lebih dari 750.000 pasien yang menjalani operasi per tahun di Amerika Serikat. Insidens hernia inguinalis lateralis yang mengalami inkarserata atau strangulata bervariasi 5-15\% pada seluruh dunia. Hernia inguinalis inkarserata dan strangulata merupakan kasus akut abdomen yang harus segera ditangani oleh karena dapat memengaruhi morbiditas (19-30\%) dan juga mortalitas $(1,4-13,4 \%) .{ }^{3,4}$

Pengobatan operatif merupakan satusatunya pengobatan hernia inguinalis yang rasional. Indikasi operasi sudah ada saat diagnosis ditegakkan. Hernia inguinalis lateralis pada anak-anak harus diperbaiki secara operatif tanpa penundaan, karena adanya risiko komplikasi yang besar terutama inkarserata, strangulata, termasuk gangren saluran cerna (usus), testis, serta peningkatan risiko infeksi dan rekurensi yang mengikuti tindakan operatif. ${ }^{1}$

\section{METODE PENELITIAN}

Penelitian ini bersifat deskriptif retrospektif dari data rekam medis (data sekunder) pasien hernia inguinalis lateralis di RSUP Prof. Dr. R. D. Kandou Manado. Subjek penelitian ialah semua data rekam medik pasien hernia inguinalis lateralis di RSUP Prof. Dr. R. D. Kandou Manado periode Agustus 2012 - Juli 2014. Variabel penelitian yaitu umur, jenis kelamin, letak hernia, jenis menurut perlangsungan hernia, dan penanganan.

\section{HASIL PENELITIAN}

Berdasarkan penelitian yang telah dilakukan secara deskriptif retrospektif pada pasien hernia inguinalis lateralis di RSUP Prof. DR. R. D. Kandou Manado periode Agustus 2012-Juli 2014 didapatkan pasien hernia inguinalis lateralis sebanyak 146 pasien. Data diambil dari rekam medis berupa nama, umur, jenis kelamin, letak, jenis menurut perlangsungan hernia dan penanganan.

Tabel 1 menunjukkan dari total 146 pasien hernia inguinalis lateralis didapatkan pada bulan Agustus- Desember tahun 2012 sebanyak 35 pasien, tahun 2013 sebanyak 59 pasien dan bulan Januari-Juli tahun 2014 sebanyak 67 pasien (Tabel 1).

Tabel 1. Distribusi pasien hernia inguinalis lateralis di RSUP Prof. Dr. R. D. Kandou Manado periode Agustus 2012 - Juli 2014

\begin{tabular}{ccc}
\hline Periode & $\begin{array}{c}\text { Jumlah } \\
\text { Pasien }\end{array}$ & $\%$ \\
\hline Agustus - Desember & 35 & $24,0 \%$ \\
2012 & 59 & $40,4 \%$ \\
2013 & 52 & $35,6 \%$ \\
Januari - Juli 2014 & 146 & 100,0 \\
Total &
\end{tabular}

Dari data distribusi pasien hernia inguinalis lateralis berdasarkan umur didapatkan kelompok umur terbanyak yaitu manula/ diatas 65 tahun sebanyak 40 pasien (27,4\%) (Tabel 2).

Data distribusi pasien hernia inguinalis lateralis berdasarkan jenis kelamin menunjukkan bahwa hernia inguinalis lateralis paling sering terjadi pada laki-laki yaitu 145 pasien (99,3\%) sedangkan pada perempuan hanya pada 1 orang pasien (0,7\%) (Tabel 3).

Tabel 4 menunjukkan bahwa letak hernia inguinalis lateralis tersering yaitu di sebelah kanan dengan 88 pasien (60,3\%), hernia inguinalis lateralis di sebelah kiri 56 pasien (38.4\%) dan hernia inguinalis lateralis bilateral 2 pasien $(1,4 \%)$. 
Tabel 2. Distribusi pasien hernia inguinalis lateralis berdasarkan umur

\begin{tabular}{|c|c|c|}
\hline Umur & $\begin{array}{c}\text { Jumlah } \\
\text { pasien }\end{array}$ & $\%$ \\
\hline $\begin{array}{c}\text { Balita } \\
\text { (0-5 thn) }\end{array}$ & 17 & 11,6 \\
\hline $\begin{array}{c}\text { Kanak-kanak } \\
\text { (5-11 thn) }\end{array}$ & 6 & 4,1 \\
\hline $\begin{array}{c}\text { Remaja Awal } \\
\text { (12-16 thn) }\end{array}$ & - & 0 \\
\hline $\begin{array}{l}\text { Remaja Akhir } \\
\text { (17-25 thn) }\end{array}$ & 8 & 5,5 \\
\hline $\begin{array}{c}\text { Dewasa Awal } \\
\text { (26-35 thn) }\end{array}$ & 12 & 8,2 \\
\hline $\begin{array}{c}\text { Dewasa Akhir } \\
\text { (36-45 thn) }\end{array}$ & 11 & 7,5 \\
\hline $\begin{array}{l}\text { Lansia Awal } \\
\text { (46-55 thn) }\end{array}$ & 21 & 14,4 \\
\hline $\begin{array}{l}\text { Lansia Akhir } \\
\text { (56-65 thn) }\end{array}$ & 31 & 21,2 \\
\hline $\begin{array}{l}\text { Manula } \\
\text { (>65 thn) }\end{array}$ & 40 & 27,4 \\
\hline Total & 146 & $\begin{array}{c}100,0 \\
\%\end{array}$ \\
\hline
\end{tabular}

Tabel 3. Distribusi pasien hernia inguinalis lateralis berdasarkan jenis kelamin

\begin{tabular}{ccc}
\hline \multirow{2}{*}{ Jenis Kelamin } & $\begin{array}{c}\text { Jumlah } \\
\text { Pasien }\end{array}$ & $\%$ \\
\hline Laki-laki & 145 & 99,3 \\
Perempuan & 1 & 0,7 \\
Total & 146 & 100,0 \\
\hline
\end{tabular}

Tabel 4. Distribusi letak hernia inguinalis lateralis

\begin{tabular}{ccc}
\hline Letak & $\begin{array}{c}\text { Jumlah } \\
\text { Pasien }\end{array}$ & $\%$ \\
\hline Kiri & 56 & 38,4 \\
Kanan & 88 & 60,3 \\
Bilateral & 2 & 1,4 \\
Total & 146 & 100,0 \\
\hline
\end{tabular}

Berdasarkan Tabel 5 didapatkan jenis menurut perlangsungan hernia terbanyak yaitu reponibel sebanyak 108 pasien (74,0\%)

Tabel 6 menunjukkan bahwa pasien hernia inguinalis lateralis di RSUP Prof. Dr. R. D. Kandou Manado yang dioperasi sebanyak 139 pasien, dimana yang menjalani operasi herniotomi sebanyak 23 pasien (15,8\%), herniotomi dengan hernioplasti sebanyak 9 pasien (6,2\%), herniotomi dengan mesh sebanyak 107 pasien $(73,3 \%)$, dan yang tidak dioperasi sebanyak 7 pasien $(4,8 \%)$.

Tabel 5. Distribusi jenis menurut perlangsungan hernia

\begin{tabular}{ccc}
\hline Jenis & $\begin{array}{c}\text { Jumlah } \\
\text { Pasien }\end{array}$ & $\%$ \\
\hline Reponibel & 108 & 74,0 \\
Ireponibel & 18 & 12,3 \\
Inkarserata & 7 & 4,8 \\
Strangulata & 13 & 8,9 \\
Total & 146 & 100,0 \\
\hline
\end{tabular}

Tabel 6. Penanganan hernia inguinalis lateralis di RSUP Prof. Dr. R. D. Kandou Manado periode Agustus 2012 - Juli 2014

\begin{tabular}{ccc}
\hline Penanganan & $\begin{array}{c}\text { Jumlah } \\
\text { Pasien }\end{array}$ & $\%$ \\
\hline Herniotomi & 23 & 15,8 \\
Herniotomi + & 9 & 6,2 \\
Hernioplasti & & \\
Herniotomi + & 107 & 73,3 \\
Mesh & 7 & 4,8 \\
Tidak Operasi & 146 & 100,0 \\
Total & & \\
\hline
\end{tabular}

\section{BAHASAN}

Pada penelitian ini didapatkan 146 pasien hernia inguinalis lateralis yang pernah dirawat di RSUP Prof. Dr. R. D. Kandou Manado periode Agustus 2012 Juli 2014. Data diambil dari rekam medis di RSUP Prof. Dr. R. D. Kandou Manado berupa nama, umur, jenis kelamin, letak hernia, jenis menurut perlangsungan hernia, dan penanganan.

Berdasarkan hasil penelitian didapatkan pasien hernia inguinalis lateralis sebanyak 146 pasien dengan distribusi pada bulan Agustus-Desember tahun 2012 sebanyak 35 pasien (24,0\%), tahun 2013 sebanyak 59 pasien $(40,4 \%)$ dan bulan Januari-Juli tahun 2014 sebanyak 52 pasien (35,6\%).

Dari data distribusi pasien hernia inguinalis lateralis berdasarkan umur didapatkan pasien hernia inguinalis lateralis 
terbanyak pada kelompok umur $>65$ tahun yaitu sebanyak 40 pasien (27,4\%). Penelitian yang dilakukan Ruhl dan Everhart pada tahun 2007 melaporkan bahwa kelompok umur dewasa memiliki angka kejadian terbanyak. Hasil penelitian ini diperkuat oleh teori Scott Kahan yang menyatakan bahwa pertambahan usia berbanding lurus dengan tingkat kejadian hernia. Hernia inguinalis lateralis dapat terjadi pada semua umur, namun tersering pada usia antara 45-75 tahun.,

Dari data distribusi pasien hernia inguinalis lateralis berdasarkan jenis kelamin didapatkan pasien laki-laki berjumlah 145 orang $(99,3 \%)$ dan perempuan berjumlah 1 orang $(0,7 \%)$. Data ini jelas menunjukkan bahwa hernia inguinalis lateralis lebih sering terjadi pada laki-laki. Hal ini ditunjang sesuai data kepustakaan yang menyatakan bahwa hernia inguinalis lateralis sering dijumpai pada laki-laki. Angka kejadian pada lakilaki 12 kali lebih sering dibanding perempuan. Prevalensi hernia inguinalis pada laki-laki dipengaruhi oleh umur. Menurut Linda A. dengan bertambahnya umur, dinding otot yang mempertahankan agar organ tubuh tetap pada tempatnya melemah dan mengendur sehingga mempercepat terjadinya hernia. ${ }^{2,7}$

Terdapat beberapa faktor yang dapat menyebabkan terjadinya hernia inguinalis lateralis, antara lain: kelemahan aponeurosis dan fasia transversalis, prosesus vaginalis yang terbuka, tekanan intra abdomen yang meninggi secara kronik, hipertrofi prostat, konstipasi, ascites, kelemahan otot dinding perut karena usia, defisiensi otot, dan hancurnya jaringan penyambung oleh karena merokok, penuaan atau penyakit sistemik. ${ }^{8}$

Dari hasil penelitian, distribusi letak hernia inguinalis lateralis didapatkan letak di sebelah kiri sebanyak 56 pasien $(38,4 \%)$, disebelah kanan sebanyak 88 pasien $(60,3 \%)$ dan bilateral sebanyak 2 pasien $(1,4 \%)$. Data ini menunjukkan bahwa letak hernia inguinalis lateralis terbanyak yaitu disebelah kanan. Hal yang sama juga dilaporkan pada penelitian yang dilakukan di RSUP H. Adam Malik Medan, yaitu hernia inguinalis lateralis yang terletak disebelah kanan merupakan kasus terbanyak selama periode Juli 2008 -Juli 2010. ${ }^{9} \quad$ Menurut teori kepustakaan, dijelaskan bahwa karena testis yang kiri turun terlebih dahulu dari yang kanan, maka kanalis inguinalis yang kanan lebih sering terbuka. Hal yang sama juga dijelaskan oleh Malangoni dan Rosjen bahwa hernia inguinalis lateralis lebih sering terjadi di sebelah kanan karena penurunan testis sebelah kanan yang terjadi lebih lambat. ${ }^{10}$

Berdasarkan distribusi jenis menurut perlangsungan hernia (Tabel 5) didapat-kan hernia inguinalis lateralis yang bersifat reponibel yang terbanyak yaitu 108 pasien (74,0\%), ireponibel 18 pasien (12,3\%), inkarserata 7 pasien $(4,8 \%)$ dan strangulata 13 pasien (8,9\%). Hernia reponibel yaitu bila isi hernia dapat keluar masuk tetapi kantungnya menetap. Isinya tidak serta merta muncul secara spontan, namun terjadi bila terdapat gaya gravitasi atau tekanan intra abdominal yang meningkat. Usus keluar jika berdiri atau mengedan dan masuk lagi jika berbaring atau didorong masuk, tidak ada keluhan nyeri atau gejala obstruksi usus. ${ }^{1}$

Pada Tabel 6 dapat dilihat data mengenai penanganan hernia inguinalis lateralis di RSUP Prof. Dr. R. D. Kandou Manado periode Agustus 2012-Juli 2014. Hasil tersebut menunjukkan bahwa pasien hernia inguinalis lateralis yang menjalani operasi herniotomi dengan menggunakan mesh yang terbanyak yaitu 107 pasien (73,3\%). Hal ini sesuai dengan sumber kepustakaan yaitu sekarang ini operasi herniotomi sering disertai dengan penggunaan mesh untuk menutup atau memperkuat dinding belakang kanalis inguinalis. $^{11}$

\section{SIMPULAN}

Berdasarkan penelitian yang dilakukan dapat disimpulkan bahwa pola hernia inguinalis lateralis di RSUP Prof. Dr. R. D. Kandou Manado periode Agustus 2012-Juli 2014 menunjukkan kelompok umur 
terbanyak yang menderita hernia inguinalis lateralis ialah manula ( $>65$ tahun), jenis kelamin laki-laki merupakan mayoritas, hernia inguinalis lateralis dengan letak di sebelah kanan yang tersering, dan hernia inguinalis lateralis reponibel yang terbanyak. Penanganan hernia inguinalis lateralis yang paling sering dilakukan ialah herniotomi dengan penggunaan mesh.

\section{SARAN}

Perlu dilakukan perbaikan dalam hal penyimpanan dan penyusunan, serta kelengkapan data rekam medik pasien guna menunjang pendataan yang lengkap, akurat, dan informatif.

\section{DAFTAR PUSTAKA}

1. Rasjad C. Hernia. In: Sjamsuhidayat R, Jong WD, editors. Buku Ajar Ilmu Bedah (Edisi ke-3). Jakarta: EGC, 2010; p. 619-29.

2. Townsend, Courtney M. Hernias. Sabiston Textbook of Surgery (17th ed.). Philadelphia: Elsevier Saunders, 2004; p. 1199-217.

3. Aru W, Sudoyo. Buku Ajar Ilmu Penyakit Dalam Jilid III (Edisi V). Jakarta: Interna Publishing, 2009.

4. Sherman V, Macho JR, Brunicardi FC.
Inguinalis hernias. In: Brunicardi FC, Andersen DK, Billiar TR, Dunn DL, Hunter JG, Matthews JB, et al, editors. Schwartz's Principles of Surgery (9th ed.). New York: McGraw-Hill Companies, 2010; p. 1305-42.

5. Ruhl CE, Everhart JE. Risk factors for inguinal hernia among adults in the US population. American Journal of Epidemiology. 2007;165(10):1154-61.

6. Kahan S. Buku Ajar Ilmu Bedah. Tagerang: Binarupa Aksara, 2011.

7. Linda A. Buku Saku Keperawatan Pediatri (Edisi 5). Jakarta: EGC, 2009.

8. Jong WD. Dinding perut, hernia, retroperitoneum, dan omentum. In: Sjamsuhidayat R, editor. Buku Ajar Ilmu Bedah. Jakarta: EGC, 2004; p. 519-37.

9. Napitupulu S. Prevalensi hernia inguinalis pada anak di RSUP H. Adam Malik Medan periode Juli 2008 -Juli 2010. USU Institutional Repository.

10. Malangoni MA, Rosjen MJ. Hernias. In: Townsend. Sabiston Textbook of Surgery (18th ed.). Saunders Elsevier, 2007.

11. Fitzgibbons RJ, Ahluwalia HS. Inguinal hernia. Schwartz Manual of Surgery (8th ed.). USA: McGraw-Hills, 2006; p. 920-42. 